\title{
Navitor valve - a new TAVI solution for patients with aortic stenosis
}

\author{
Marek Grygier ${ }^{1}$, Anna Olasińska-Wiśniewska², Marcin Misterski², Bartłomiej Perek², Tomasz Urbanowicz², \\ Agata Markiewicz' , Marek Jemielity², Maciej Lesiak'
}

${ }^{1}$ Chair and $1^{\text {st }}$ Department of Cardiology, Poznan University of Medical Sciences, Poznań, Poland

${ }^{2}$ Department of Cardiac Surgery and Transplantology, Poznan University of Medical Sciences, Poznań, Poland

\author{
Correspondence to: \\ Anna Olasińska-Wiśniewska, \\ MD, PhD, \\ Department of Cardiac Surgery \\ and Transplantology, \\ Poznan University of Medical \\ Sciences, \\ Długa 1/2, 61-848 Poznań, \\ Poland, \\ phone: +48 618549210 , \\ e-mail: \\ annaolasinska@ump.edu.pl \\ Copyright by the Author(s), 2021 \\ Kardiol Pol. 2021. \\ 79 (11): 1278-1279; \\ DOI: 10.33963/KP.a2021.0086 \\ Received: \\ July 12, 2021 \\ Revision accepted: \\ August 15, 2021 \\ Published online: \\ August 15, 2021
}

A 71-year-old man with a history of severely symptomatic aortic stenosis, peripheral artery disease, chronic coronary syndrome, after previous percutaneous coronary interventions and with end-stage kidney disease receiving dialysis, was admitted to our hospital. Echocardiography revealed a calcified aortic valve with mean and maximum gradients of 60 and $104 \mathrm{~mm} \mathrm{Hg}$, respectively, mild aortic regurgitation, moderate tricuspid regurgitation, severe secondary pulmonary hypertension, and mild contractility impairment with preserved left ventricular ejection fraction. Severe aortic valve calcification and narrowing atherosclerotic lesions in femoral arteries were shown on computed tomography (Supplementary material, Figure S1). The perioperative risk was high (logistic EuroSCORE 21.32; EuroSCORE II $4.1 \%$ ) thus the heart team decided to qualify the patient for transcatheter aortic valve implantation (TAVI).

The procedure (the first one in Poland) was performed on June 9, 2021, in the hybrid room under local anesthesia. The left femoral artery access was achieved by the surgical cutdown and a $14 \mathrm{~F}$ sheath was inserted. After valve predilatation with Nucleus Z-Med II $23 \mathrm{~mm} \times 4.0 \mathrm{~cm}$ balloon (NuMED, Hopkinton, NJ, USA) over Safari wire, the $29 \mathrm{~mm}$ Navitor valve (Abbott, Abbott Park, IL, USA) was successfully implanted with one reposition needed to obtain proper valve position (Figure 1). Since moderate paravalvular leak (PVL) was observed, postdilatation with Nucleus Z-Med II $26 \mathrm{~mm} \times 4.0 \mathrm{~cm}$ balloon (NuMED, Hopkinton, NJ, USA) was performed with complete PVL elimination and mean transvalvular gradient decrease to $8 \mathrm{~mm} \mathrm{Hg}$ (Supplemen- tary material, Figure S2). The post-operative period was uneventful, without conduction disturbances, and the patient was discharged home on day 3.

TAVI is an established and safe therapeutic option for patients with severe aortic stenosis [1-3]. The self-expanding Navitor valve (successor of Portico valve) (Figure 1) is the newest TAVI solution for patients with severe aortic stenosis, which is available in Poland and some other European countries. The prosthesis has intra-annular leaflets and large frame cells, which enhances coronary access in case of future interventions and is currently available in four sizes: $23 \mathrm{~mm}, 25 \mathrm{~mm}, 27 \mathrm{~mm}$, and $29 \mathrm{~mm}$. The key innovation is an active outer fabric cuff designed to reduce the PVL risk by close integration to the native valve. The cuff actively synchronizes to the cardiac cycle and expands to fill calcification-related gaps between the aortic annulus and prosthesis. The Navitor is implanted using Abbott's FlexNav delivery system (Abbott, Plymouth, MN, USA) designed to improve flexibility and stability of the delivery even in patients with minimal femoral artery diameters $(>5 \mathrm{~mm}$ ). The low $14 \mathrm{~F}$ profile of the delivery system reduces vascular complication risks.

In our patient, the access was obtained through a surgical cut-down due to significant atherosclerotic changes in the femoral arteries, which is a standard of care in our center $[4,5]$. One repositioning maneuver was easily obtained and, according to the manufacturer's recommendation, up to 3 attempts may be undertaken during the procedure.

The safety and efficacy of the new valve were evaluated in the Portico NG prospec- 

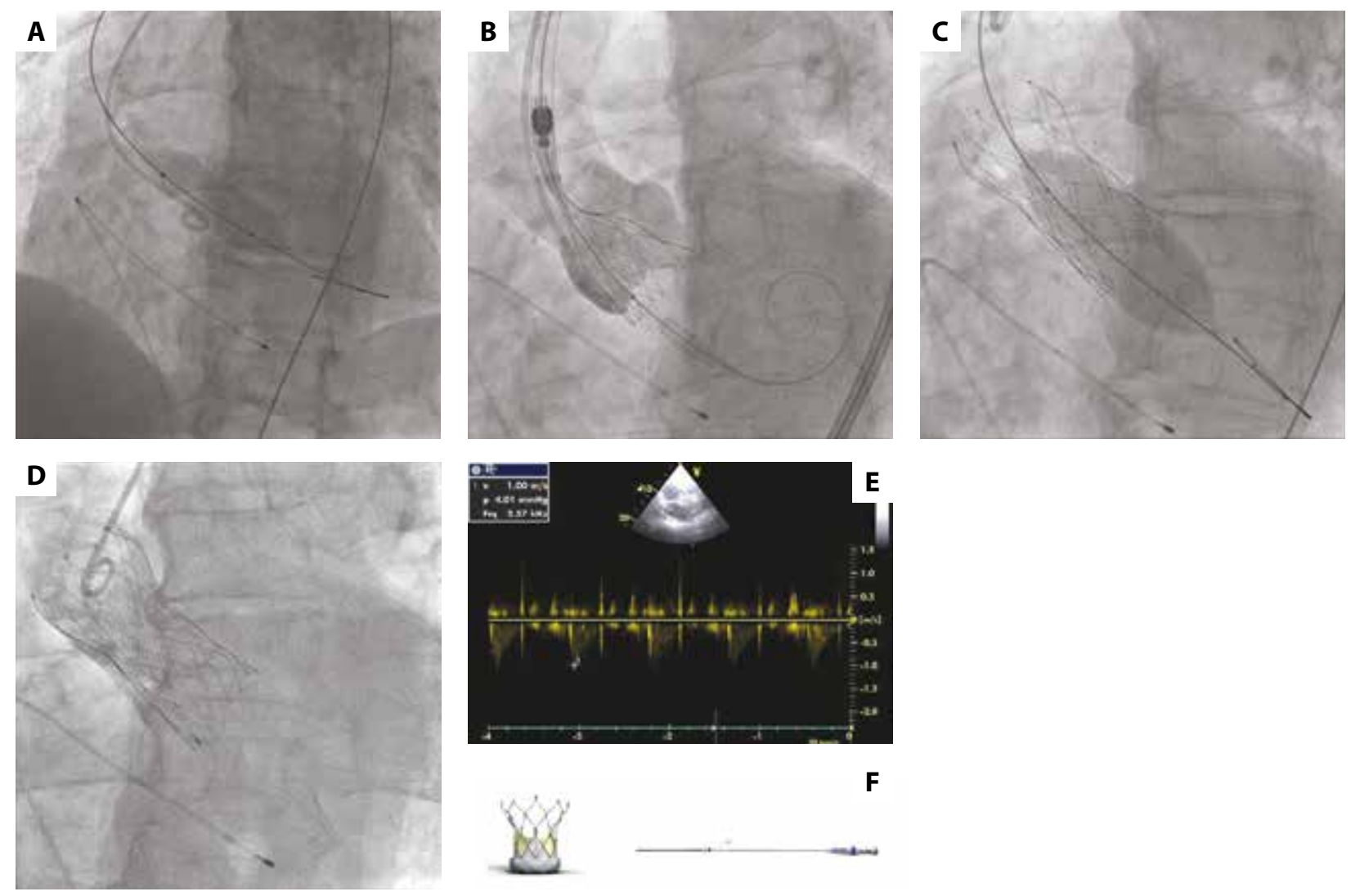

Figure 1. A. Native aortic valve predilatation with Nucleus balloon over Safari wire. B. Partially implanted Navitor valve - contrast injection showing proper implantation height and preserved flow to coronary arteries. C. Postdilatation of implanted Navitor valve in order to decrease the rate of paravalvular leak (PVL). D. Final aortogram showing the proper position of implanted valve with no PVL. E. ECHO examination after the procedure - low maximum transprosthesis gradient. F. Navitor transcatheter aortic valve implantation (TAVI) with FlexNav delivery system

tive, multi-center study conducted in 120 patients with high or extreme surgical risks. The first results of the trial were presented during EuroPCR 2021, showing 0\% 30-day mortality with none or trace PVL in $80 \%$ of patients, with the remaining $20 \%$ showing only mild PVL — none had a moderate or severe leak. Moreover, effective orifice areas were comparable to supra-annular valves, and low single-digit gradients were noted. Fifteen percent of patients required pacemaker implantation after TAVI with Navitor, however, it should be pointed out that the majority of them had presented with pre-existing conduction disturbances. A 5-year long follow-up is ongoing. Moreover, the VANTAGE - an international, pre-market clinical trial in patients at low-to-intermediate risk has just started.

\section{Supplementary material}

Supplementary material is available at https://journals.viamedica.pl/kardiologia_polska.

\section{Article information}

Conflict of interests: None declared.

Open access: This article is available in open access under Creative Common Attribution-Non-Commercial-No Derivatives 4.0 International (CC BY-NC-ND 4.0) license, allowing to download articles and share them with others as long as they credit the authors and the publisher, but without permission to change them in any way or use them commercially. For commercial use, please contact the journal office at kardiologiapolska@ptkardio.pl.

How to cite: Grygier M, Olasińska-Wiśniewska A, Misterski M, et al. Navitor valve - a new TAVI solution for patients with aortic stenosis. Kardiol Pol. 2021; 79(11): 1278-1279, doi: 10.33963/KP.a2021.0086.

\section{REFERENCES}

1. Dębiński M, Domaradzki W, Fil W, et al. Longterm outcomes of transcatheter self-expanding aortic valve implantations in inoperable and high surgical-risk patients with severe aortic stenosis: a single-center single-valve registry. Kardiol Pol. 2021; 79(3): 319-326, doi: 10.33963/KP.15821, indexed in Pubmed: 33599461.

2. Piroli $F$, Franchin $L$, Bruno $F$, et al. New advances in the prevention of transcatheter aortic valve implantation failure: current and future perspectives. Kardiol Pol. 2020; 78(9): 842-849, doi: 10.33963/KP.15522, indexed in Pubmed: 32692029.

3. Olasińska-Wiśniewska A, Misterski M, Araszkiewicz A, et al. First implantation of the Acurate neo 2 prosthesis in a patient with aortic stenosis in Poland. Kardiol Pol.2021; 79(2):207-208, doi: 10.33963/KP.15757, indexed in Pubmed: 33463993.

4. Kochman J, KoltowskiŁ, HuczekZ, et al. Complete percutaneous approach versus surgical access in transfemoral transcatheter aortic valve implantation: results from a multicentre registry. Kardiol Pol. 2018; 76(1):202-208, doi: 10.5603/KP.a2017.0205, indexed in Pubmed: 29131296.

5. Olasińska-Wiśniewska A, Grygier M, Lesiak M, et al. Femoral artery anatomy-tailored approach in transcatheter aortic valve implantation. Postępy Kardiol Interwencyjnej. 2017; 13(2): 150-156, doi: 10.5114/pwki.2017.68050, indexed in Pubmed: 28798786. 